\title{
$E$ phage gene transfection enhances sensitivity of lung and colon cancer cells to chemotherapeutic agents
}

\author{
ANA R. RAMA ${ }^{1}$, JOSE PRADOS ${ }^{1}$, CONSOLACION MELGUIZO ${ }^{1}$, RAUL ORTIZ ${ }^{1}$, PABLO J. ÁLVAREZ ${ }^{1}$, \\ FERNANDO RODRÍGUEZ-SERRANO ${ }^{1}$, FIDEL HITA ${ }^{2}$, JUAN L. RAMOS ${ }^{3}$, \\ MIGUEL BURGOS $^{4}$ and ANTONIA ARANEGA ${ }^{1}$ \\ ${ }^{1}$ Institute of Biopathology and Regenerative Medicine (IBIMER), Granada; ${ }^{2}$ Department of Health Science, \\ University of Jaen, Jaen; ${ }^{3}$ CSIC-Estación Experimental del Zaidín, Department of Environmental Protection; \\ ${ }^{4}$ Department of Genetics and the Institute of Biotechnology, Centro de Investigaciones Biomedicas CIBM \\ (Biomedicine Research Center), Granada, Spain
}

Received July 1, 2010; Accepted August 20, 2010

\section{DOI: 10.3892/ijo_00000803}

\begin{abstract}
The $E$ gene from $\Phi$ X174 encodes a membrane protein with a toxic domain that leads to a decrease in the tumour cell growth rate. With the aim of improving the antitumour effect on lung and colon cancer cells of the currently used chemotherapeutic drugs such as gemcitabine, carboplatin and paclitaxel, and 5-fluorouracil (5FU) plus folinic acid (FA) with irinotecan or oxaliplatine, we investigated a new combined therapy using these drugs associated to the transfection of $E$ gene. Our results showed that $E$ gene was able to decrease proliferation rate in A-549 and T-84 cells by inducing apoptotic the mitochondrial pathway. Significantly greater inhibition of proliferation was obtained using drugs in combination with $E$ gene in comparison to single-agent treatments or controls. $E$ gene combined with paclitaxel had the greatest effect on A-549 cells and combined with 5FU/FA/oxaliplatin on T-84 cells. Antitumour mechanisms of the chemotherapeutic drugs were enhanced by $E$ gene, which itself has direct oncolytic effects inducing A-549 and $\mathrm{T}-84$ apoptosis. Our in vitro results indicate that the combined therapy of $E$ gene and cytotoxic drugs may be of potential therapeutic value as a new strategy for patients with advanced lung and colon cancer.
\end{abstract}

\section{Introduction}

Lung and colorectal cancer are two of the most frequent tumours in the developed world. During the past few years, several novel drugs have improved the clinical response of both tumour types. Paclitaxel (Pac), docetaxel (Doc),

Correspondence to: Dr J. Prados, Instituto de Biopatología y Medicina Regenerativa (IBIMER), Departamento Anatomía y Embriología, Facultad de Medicina, Universidad de Granada, E-18071 Granada, Spain

E-mail: jcprados@ugr.es

Key words: gene therapy, gene $E$, cytotoxic therapy, colon cancer, lung cancer gemcitabine (Gem) and vinorelbine have shown significant activity against non-small cell lung cancer (NSCLC) which represents $\sim 5-80 \%$ of all lung cancers $(1,2)$. On the other hand, new chemotherapeutic agents, such as oxaliplatin (Oxa), irinotecan (CPT-11) and capecitabine and some biologic agents have contributed considerably to the treatment of colon cancer (3). In fact, 5FU and folinic acid (FA)-based combination regimens that include Oxa and CPT-11 have shown an increase in the survival in patients with metastatic disease $(4,5)$. However, in spite of these advances, the majority of patients diagnosed of either NSCLC or colon cancer have an advanced stage of disease and a poor prognosis. A major goal of lung and colon cancer research is to improve the effectiveness of these cytotoxic agents so the development of new therapeutic strategies is necessary.

To enhance the efficacy of antitumour drugs in patients with advanced cancer is one of the main objectives of the new gene therapy systems. Positive results of these strategies have been reported in bladder, pancreas and breast cancer (6-8). In lung cancer, the telomerase-specific oncolytic adenovirus combined with Gem resulted in a synergistic cytotoxic effect (9). Adeno-associated virus (AAV) vector encoding human CD40L, which is able to activate host immune systems, has been associated with Car in lung cancer cells (A-549 cell line). The results showed an increase in the antitumor response suggesting that this combined therapy may provide an effective form of lung cancer treatment (10). Recently, we have demonstrated that the use of Pac in the same cell line associated to gef gene transfection, a gene with cell-killing function, enhanced the chemotherapeutic effect of this drug (11). Colon cancer has demonstrated to have efficacy of gene therapy cytotoxic-combined strategies. Using colon cancer cell lines (HT-29, WiDr and HCT-116) the antitumoural activity of NV1020, an oncolytic herpes simplex virus type 1 , was increased by $5 \mathrm{FU}, \mathrm{SN} 38$ or Oxa (12). On the other hand, RNA interference has been used to down-regulate the NF-кB p65 subunit increasing sensitivity to chemotherapeutic agents in the HCT116 colon cancer cell line. In fact, in vivo administration of p65 siRNA reduced 
HCT116 tumour formation in xenograft models in the presence of CPT-11 (13). These studies showed that colon cancer is a good candidate to applied gene therapy associated to cytotoxic therapy. In this context, our group developed new cancer gene therapy strategies based in the use of toxic gene which does not need a prodrug to be effective in tumour cells and which are able to enhance the activity of some citotoxic drugs (11). We showed anti-tumour actitivity of the $E$ gene, which encodes for a 91-amino acid membrane protein with lytic function $(14,15)$ thought a model in which the protein oligomerizes to form a transmembrane tunnel spanning the entire cell envelope to release the cytoplasmic contents (16). The transfection of $E$ gene in melanoma cells induced apoptosis obtaining a significant decrease in the percentage of surviving cells and in the volume of tumour induced in vivo (17).

The aim of this study is to investigate whether gene therapy with $E$ gene is able to increase the therapeutic effect of drugs used in the classical treatment of lung and colon cancer. Our results clearly demonstrate that $E$ gene significantly enhanced the anti-proliferative activity of Pac in A-549 human lung cancer cells and 5FU-FA and Oxa in T-84 human colon cancer cells. This significant reduction of growth rate in both A-549 and T-84 cell lines was mediated by an apoptotic phenomenon. These results suggest that the therapeutic association of $E$ gene with drug chemotherapy may be a promising therapy for treating patients with advanced lung or colorectal cancer.

\section{Materials and methods}

Cell culture. The lung carcinoma cell line A-549 (ATCCCCL185) and the colon carcinoma cell line T-84 (ATCC CCL-248) were grown with DEMEM (Sigma Chemical Co., St. Louis, MO), supplemented with $10 \%$ heat-inactivated foetal bovine serum (FBS), $40 \mathrm{mg} / 1$ gentamycin and $500 \mathrm{mg} / \mathrm{l}$ ampicillin (Antibióticos S.A, Spain). Cells were maintained in monolayer culture at $37^{\circ} \mathrm{C}$ in an atmosphere containing $5 \%$ $\mathrm{CO}_{2}$.

Vector construction. The $E$ gene (provided by Dr J.L. Ramos from the Zaidín Experimental Station, CSIC, Granada, Spain) was amplified by using specific primers (sense 5'-CATGGT ACGCTGGACTTTGT-3' and antisense 5'-TCCTTCTGCAC GTAATTTTTGA-3') and subcloned into the pcDNA3.1 vector following the manufacturer's instructions (Invitrogen). The resulting plasmid pcDNA3.1 was analysed using the T7 primer 5'-TAATACGACTCACTATAGGG-3'. Plasmid DNA was amplified in E. coli DH5a (Qiagen, Barcelona, Spain). Transfection conditions were optimised by using the pcDNA3.1/lacZ encoding ß-galactosidase. The intracellular localization was studied by creating a fusion protein between lysis protein E and V5 epitope (pcDNA3.1/E).

Transfection. One day before transfection, A-549 and T-84 cells were seeded into 24 -well plates $\left(10^{4}\right.$ cells per well). Briefly, a transfection mixture was prepared by adding the serum-free medium and 1.2 $\mu \mathrm{l}$ FuGENE-6 reagent (Roche Diagnostic, Barcelona, Spain). After 5 min of incubation at room temperature, $0.4 \mu \mathrm{g}$ of pcDNA3.1/E was added. A-549 and T-84 cells (70\% confluence) were transfected with a final volume of $20 \mu 1$ of transfection mixture in $500 \mu 1$ of culture medium per well. Experiments were performed in two groups: A-549 and T-84 cells transfected at day 1 alone (A-549/TE* and T-84/TE*) and A-549 and T-84 cells transfected at days 1, 3 and 5 (A-549/TE** and T-84/TE**). A-549 and T-84 cells transfected with empty vector were used as controls.

Reverse transcription-PCR (RT-PCR). Upregulation of mRNA expression of $E$ cDNA was determined by RT-PCR. Total RNA was extracted from transfected and parental cells with the Rneasy mini kit (Qiagen), and cDNA was generated by means of the Promega reverse transcription system using total cellular RNA $(1 \mu \mathrm{g})$. PCR amplification of gene $E$ took place under the above-described conditions and was run on a $1.8 \%$ agarose gel and visualized by ethidium bromide staining. RNA integrity was assessed by amplification of $B$-actin mRNA (sense 5'-ATCATGTTTGAGACCTTCAA-3' and antisense 5'-CATCTCTTGCTCGAAGTCCA-3'). Images were scanned and analysed using a Bio-Rad documentation system (Quantity One Analysis Software).

Microscopic analysis. E/V5 fusion protein expression was confirmed in A-549- and T-84 pcDNA3.1/E-transfected cells using an anti-V5-FITC antibody (Invitrogen). Briefly, the cells were grown on coverslips, washed with PBS, fixed in $100 \%$ methanol (room temperature) for $5 \mathrm{~min}$, blocked with $1 \%$ bovine serum albumin/PBS, and then incubated with anti-V5-FITC antibody diluted (1:500) in 1\% bovine serum albumin/PBS for $1 \mathrm{~h}$. DAPI (Invitrogen) solution (100 $\mathrm{nM})$ was used for nuclear staining. The cells were then rinsed briefly with PBS, mounted and visualized using fluorescent microscopy analysis (Nikon Eclipse Ti, Nikon Instruments Inc. NY, USA). V5 was excited at $488 \mathrm{~nm}$ and DAPI nuclear stain at $364 \mathrm{~nm}$. Moreover, optical and transmission electronic microscopy (Hitachi H7000 transmission electron microscope) was used, according to Prados et al (11) to determine morphological changes in parental and transfected A-549 and T-84 cells.

In vitro cell proliferation assay. Cells were seeded in 24-well plates $\left(10^{4}\right.$ cells per well). MTT [3-(4,5-dimethylthiazol-2yl)-2,5-diphenyltetrazolium bromide] solution $(5 \mathrm{mg} / \mathrm{ml})$ was added to each well $(20 \mu \mathrm{l})$ and incubated $4 \mathrm{~h}$ at $37^{\circ} \mathrm{C}$. Then, $200 \mu 1$ of dimethylsulfoxide (DMSO) was added to each well after the medium was removed. Optical density was determined using a Titertek multiscan colorimeter (Flow, Irvine, CA) at 570 and $690 \mathrm{~nm}$. Cells transfected with empty vector were used as controls. The proliferation effect of the combined gene and cytotoxic therapy was determined for 7 days using Pac, Gem and Car (all drugs to 100, 50 and $1 \mu \mathrm{M}$ ) for A-549 cells $(18,19)$ and $5 \mathrm{FU}(5000,500$ and $5 \mu \mathrm{M}), \mathrm{CPT}-11(200$, 50 and $10 \mu \mathrm{M})$, Oxa $(100,10$ and $0.5 \mu \mathrm{M})$ and FA $(5 \mu \mathrm{M})$ for T-84 cells $(20,21)$.

Mitochondrial transmembrane potential and apoptosis analysis. Changes in mitochondrial transmembrane potential were evaluated by labelling parental and transfected A-549 and T-84 cells with $\mathrm{DiOC}_{6}(40 \mathrm{nM})$ for $15 \mathrm{~min}$ at $37^{\circ} \mathrm{C}$. Cells 
A

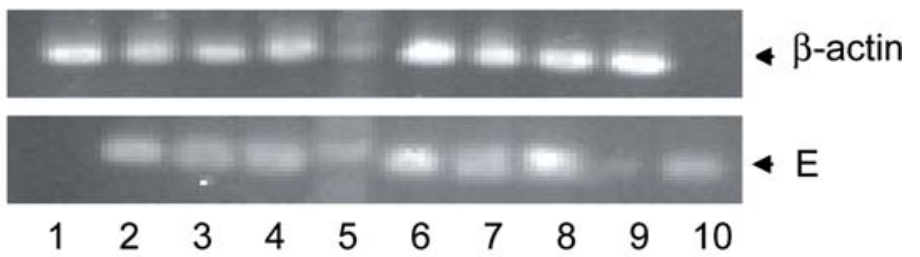

B
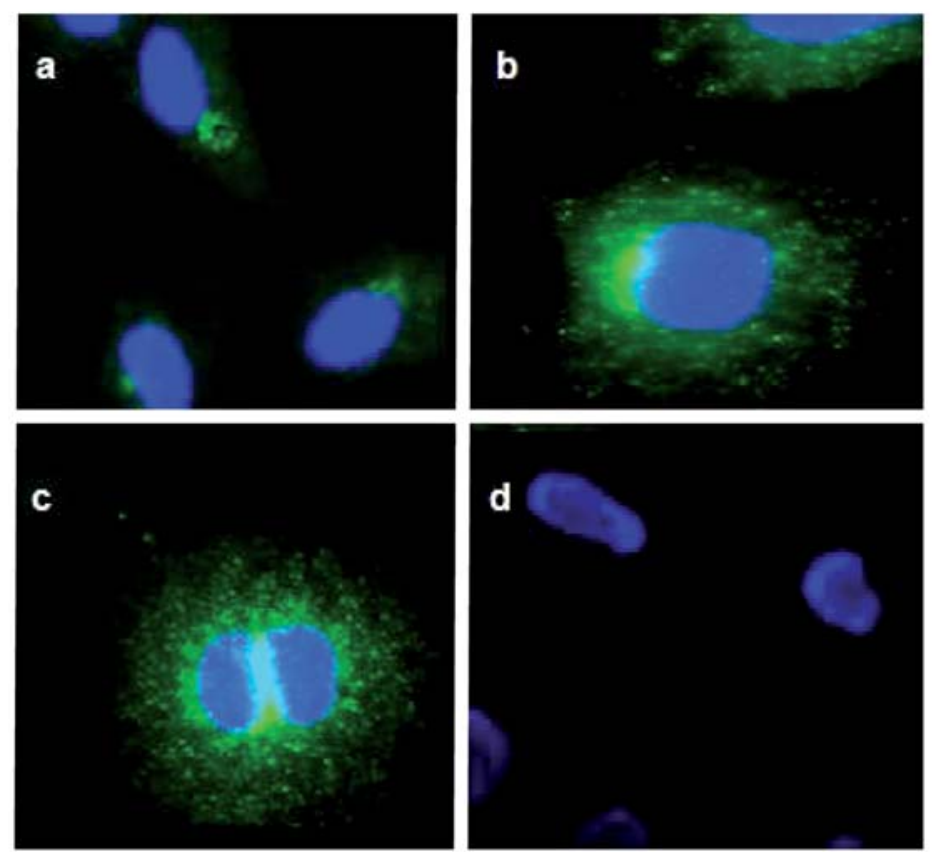

Figure 1. Determination of $E$ gene expression on A-549 and T-84 cells. (A) $E$ gene expression in A-549/TE* and T-84/TE*. Amplified PCR products of $E$ and $\beta$-actin mRNA were visualized with ethidium bromide. Lane $1, \mathrm{~T}-84$ cells (negative control); lane 2 , T-84/TE* at 2 days; lane 3 , T-84/TE* at 5 days; lane 4 , T-84/TE* at 7 days; lane 5, molecular weight; lane 6, A-549/TE* at 2 days; lane 7, A-549/TE* at 5 days; lane 8, A-549/TE* at 7 days; lane 9, A-549 cells (negative control); lane 10, pcDNA3.1/E vector (positive control). (B) Subcellular localization of the E/V5 fusion protein expressed in T-84/TE* cells. Recombinant E protein (E-V5) detected by anti-V5-FITC antibody is shown in green and cell nuclei stained by DAPI in blue. Twenty-four hours after transfection $(\mathrm{a}, \mathrm{x} 40)$ the fluorescence pattern was dotted and localized in the cell cytoplasm. The intensity of staining progressively increased after 48 (b, $\mathrm{x} 40$ ) and $72 \mathrm{~h}(\mathrm{c}, \mathrm{x} 40)$ of transfection. T-84 control cells showed no green staining (d, x20).

were then washed twice with PBS and analyzed directly on a flow cytometer using excitation and emission wavelengths of 495 and $525 \mathrm{~nm}$, respectively. Apoptosis was determined by FACScan flow cytometer using Annexin V-FITC apoptosis detection kit I (BD Pharmingen, San Diego, CA, USA).

Cellular fractionation and Western blot. Cells were harvested and lysed in sample buffer consisting of $62.5 \mathrm{mM}$ Tris $\mathrm{HCl}$ (pH 6.8), 10\% glycerol, 2\% SDS, 5\% 2-mercaptoethanol, $0.5 \%$ bromophenol blue and $100 \mathrm{mM}$ dithiothreitol. Proteins were separated on $10 \%$ SDS-polyacrylamide gels and electroblotted onto Immobilon-P membranes (Millipore, Bedford, MA, USA). The antibodies used in this study were rabbit polyclonal IgG anti-caspase-3, anti-caspase-9 and anticaspase-8 (Santa Cruz Biotech, Santa Cruz, CA) and antiB-actin (Sigma Chemical Co.). Blots were treated with blocking solution (20 mM Tris, $0.9 \mathrm{NaCl}, 10 \%$ non-fat milk) for $3 \mathrm{~h}$ and then incubated with the rabbit polyclonal primary antibody (1:1000 dilution) (Santa Cruz Biotech) overnight at $4^{\circ} \mathrm{C}$. After addition of peroxidase-conjugated secondary antibody, proteins were added with ECL Western blotting detection reagents (Amersham Biosciences, USA) and analyzed using the Fuji LAS-3000 imaging system (Japan). In order to analyze the redistribution of cytochrome $\mathrm{c}$ during apoptosis, cells were fractionated into cytosolic and membranebound fractions. For this purpose, cells were exposed to $0.05 \%$ digitonin (Sigma) in isotonic sucrose buffer $(250 \mathrm{nM}$ sucrose, $10 \mathrm{nM}$ HEPES, $10 \mathrm{nM} \mathrm{KCl}, 1.5 \mathrm{nM} \mathrm{MgCl}_{2}, 1 \mathrm{nM}$ ethylenediaminetetraacetate, and 1 EGTA; $\mathrm{pH}$ 7.1) for $2 \mathrm{~min}$ at room temperature to collect the soluble fraction as cytosolic extracts. Digitonin insoluble fraction was dissolved in $2 \%$ sodium dodecyl sulfate (SDS) buffer to collect the membranebound part. Inmunoblotting to detect cytochrome $\mathrm{c}$ was realized as described above using anti-cytochrome $\mathrm{c}$ and antiBcl-2 (Santa Cruz Biotech) to demonstrate the cellular fractionation. 


\section{A}
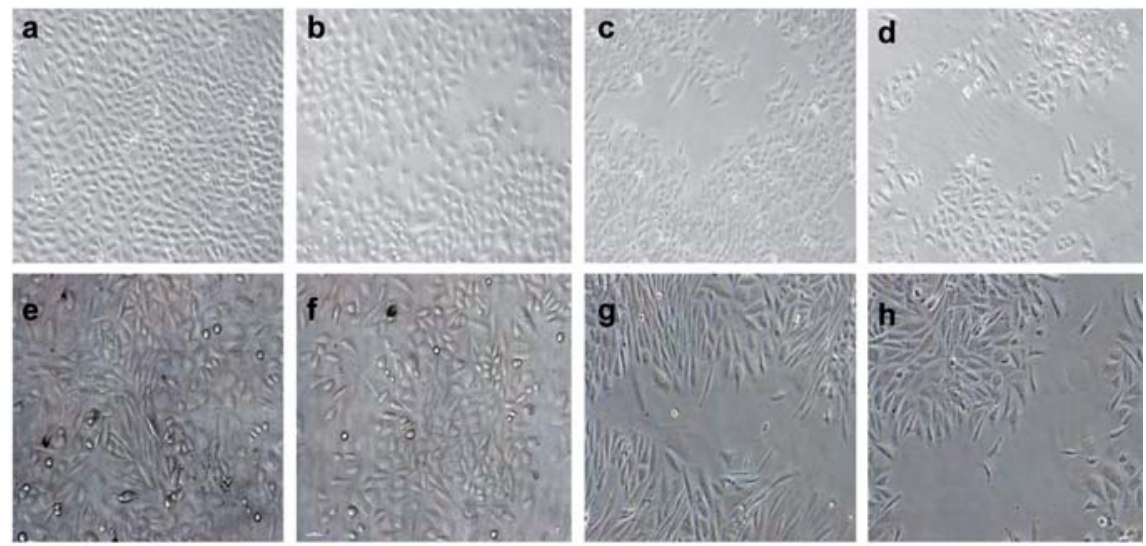

\section{B}
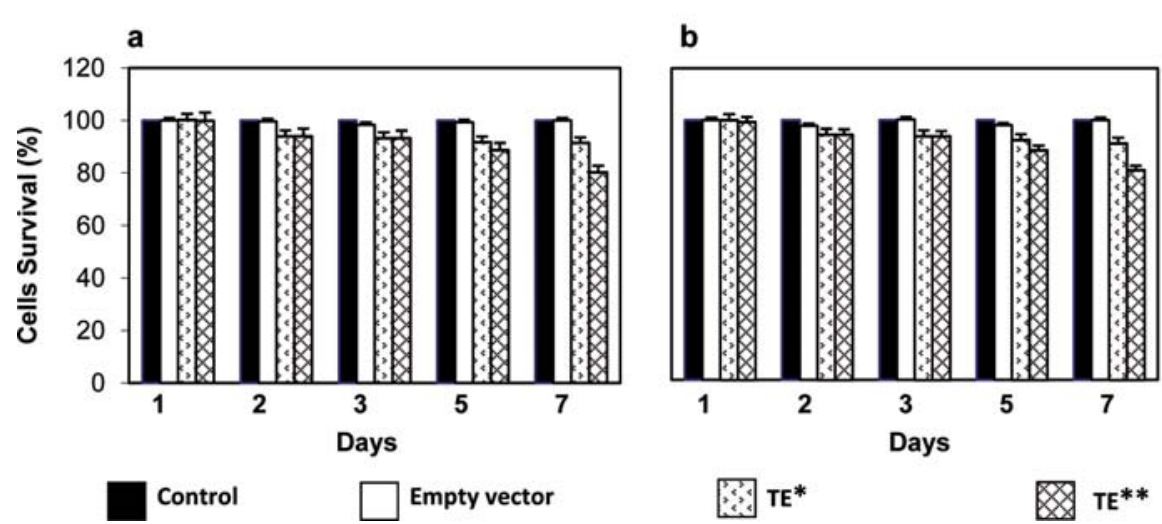

Figure 2. Morphology and proliferative changes in $E$ gene transfected A-549 and T-84 cells. (A) Phase contrast micrographs of A-549 and T-84 parental and transfected cells. Parental A-549 cells (a) grew in clumps, were typically polygonal and adhered strongly to the culture flask. Parental T-84 cells (e) showed a more spiculated morphology. Transfected A-549 and T-84 cells were rounded and easily detached from the culture flask forming an irregular monolayer culture with the progressive presence of zones without cells at 3 (b and f), 5 (c and g) and 7 days (d and h) (x40). (B) A-549, A-549/TE* and A-549/TE** cells (a) and T-84, T-84/TE* and T-84/TE** cells (b) were cultured for 7 days to determine the growth rate. A-549 and T-84 cells transfected with empty vector were used as a control. Values represent means $\pm \mathrm{SD}$ of quadruplicate cultures.

Immunohistochemical staining. Cells were grown on slides, fixed in $100 \%$ methanol (room temperature) for $5 \mathrm{~min}$ and stained with haematoxylin-eosin. Immunohistochemistry was performed using an avidin-biotin-peroxidase complex (ABC) detection kit (Dako ChemMate Detection Kit). Endogenous peroxidase activity was inhibited with $15 \mathrm{~min}$ incubation in $3 \% \mathrm{H}_{2} \mathrm{O}_{2}$ peroxidase in methanol. Non-specific antigenic sites were blocked by a 20 min step in diluted normal serum (Dako) before the sections were incubated for $1 \mathrm{~h}$ at $37^{\circ} \mathrm{C}$ with the primary antibody (rabbit polyclonal IgG anti-caspase-3, anticaspase-9 and anti-caspase-8 (Santa Cruz Biotech). Then, the sections were first incubated at RT with a biotinylated secondary antibody (Dako) for $30 \mathrm{~min}$ and second with the peroxidase-conjugated biotin-avidin complex $(\mathrm{ABC})$ for $40 \mathrm{~min}$. Finally, the peroxidase was revealed by immersion in 3,3'-diaminobenzidine-tetrahydrochloride (DAB, Dako) The section DAB colorization was inspected under the light microscope. Immunostaining of negative control included sequential elimination of the primary or secondary antibody from the staining series.

Statistical analysis. SPSS 7.5 software (SPSS, Chicago, IL) was used for all statistical analyses. Results were compared by using the Student's t-test. All data are expressed as means \pm SD. Differences were considered statistically significant at $\mathrm{P}<0.05$.

\section{Results}

$E$ gene expression and $E$ protein localization in transfected $A-549$ and $T-84$ cells. The antitumour effect of $E$ gene was analysed by transfecting A-549 and T-84 cells with the pcDNA3.1/E vector. $E$ gene expression in these cells was assessed by RT-PCR. As shown in Fig. 1A, an amplification fragment of $154 \mathrm{bp}$ was found in A-549/TE* and T84/TE* cells, indicating the effectiveness of the construction and 


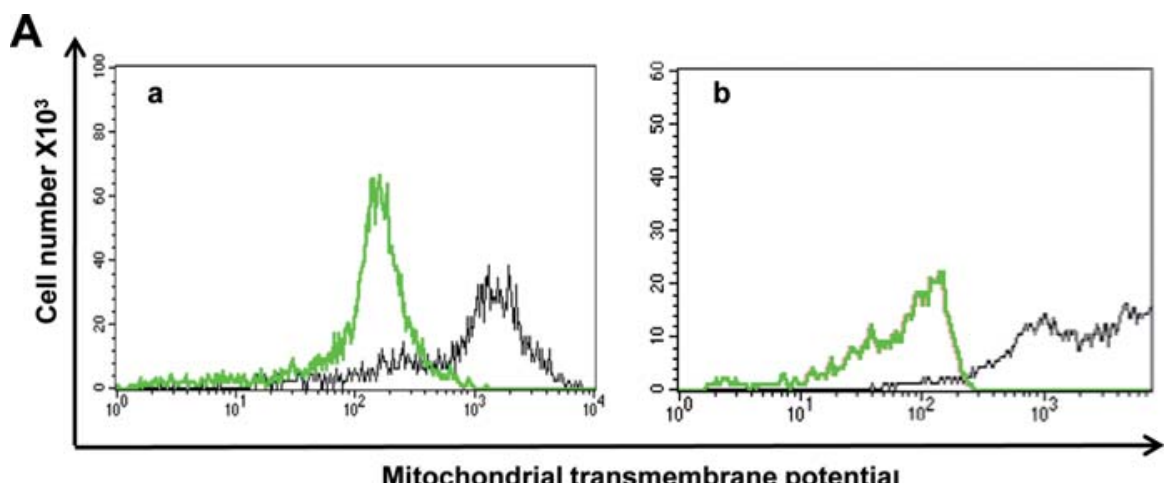

Mitochondrial transmembrane potential

\section{B}

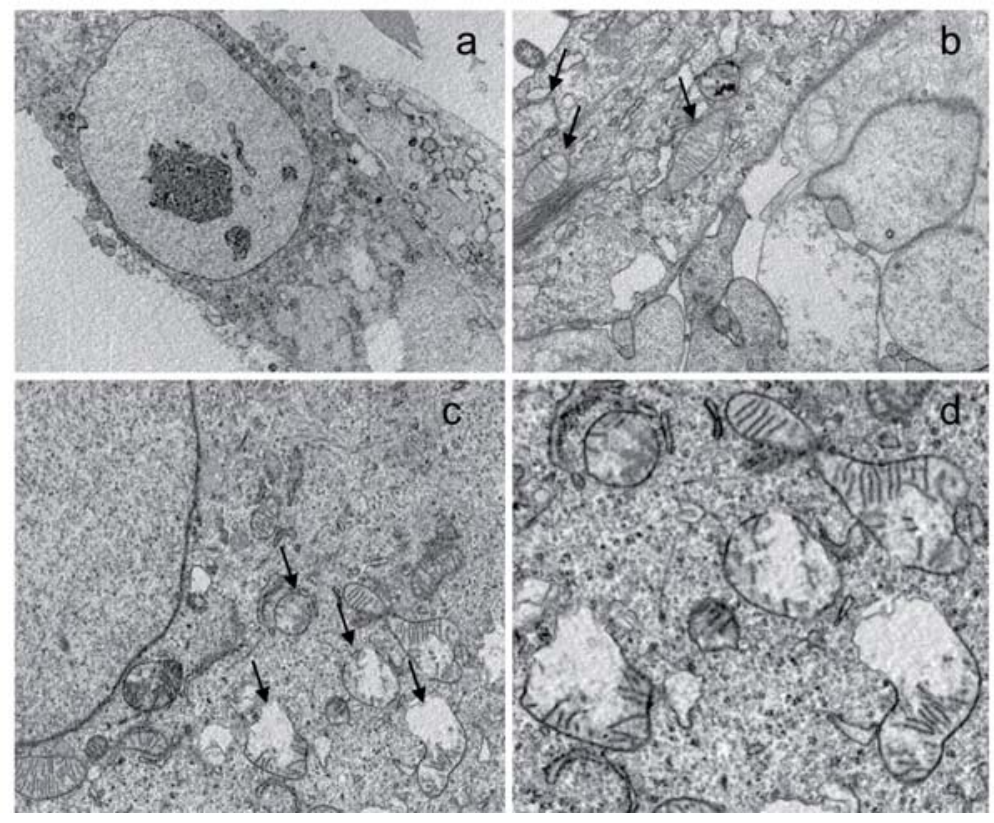

Figure 3. Mitochondrial transmembrane potential and ultrastructural changes induced by $E$ gene in A-549 and T-84 cells. (A) Flow cytometric analysis of mitochondrial membrane potential was performed using staining with $\mathrm{DiOC}_{6}$. Representative results from three individual experiments of A-549/TE* (a) and T-84/TE* (b) cells (green) after $48 \mathrm{~h}$ are shown in comparison to A-549 and T-84 cells parental cells (black), respectively. (B) Representative TEM micrographs showing ultrastructural changes in T-84 cells after $E$ gene transfection. Conventional electron microscopy of parental T-84 cells (a) showed typical tumour cells with large nucleus and light cytoplasmic complexion (x1100). T-84/TE* (3 days) showed dilated mitochondria with disrupted cristae (arrows) (b) (x6000). The presence of altered mitochondria in T-84/TE* increased at 5 (c) (x 4400) (arrows) and 7 days. A detail of the altered mitochondria (d) (x9000).

allowing its use in the subsequent in vitro experiment. The expression of the E-V5 fusion protein showed a clear signal in the T-84/TE* cell cytoplasm with a dotted fluorescence pattern at 3 day (Fig. 1B). Similar results were found in A-549/TE* (data no shown).

E gene induced morphological changes in A-549 and T-84 cells. Both A-549 and T-84 cells were attached to the bottom of the flasks with an irregular arrangement in confluent cultures (Fig. 2A). Transfected cells with empty vector showed no morphological changes with respect to the parental cell line (data not shown). However, significant differences were observed between control and $E$ gene-transfected cells which showed a progressive loss of monolayer culture uniformity over four days, with the presence of irregular zones without cells. These zones were more evident when the transfection was continuous (Fig. 2A).
E gene inhibits growth in transfected A-549 and T-84 cells. As shown in Fig. 2B, the growth of A-549 and T-84 cells transfected with the empty vector was similar to that of the parental cells. In contrast, both tumoural cell lines transfected with $E$ gene showed a significant and time-dependent decrease in growth. Slight differences were found in A-549/TE* and T-84/TE* at the day 2, 5 and $7(<10 \%)$ after transfection with $E$ gene versus empty vector transfected cultures. However, analysis of the A-549/TE** and T-84/TE** cells showed a significant modulation of growth. The determination of $\%$ of surviving cells showed an $11.3 \pm 0.6 \%$ and $11.6 \pm 1.1 \%$ (day 5 ) and $19.8 \pm 1.3 \%$ and $19.2 \pm 1.7 \%$ (day 7) decrease to A-549 and T-84 cells, respectively ( $<<0.05)$ (Fig. 2B).

E gene induced functional and morphological mitochondrial damage. Mitochondrial damage was assessed biochemically by measuring DiOC $_{6}$. At $48 \mathrm{~h}$ after transfection A-549/TE* 
A
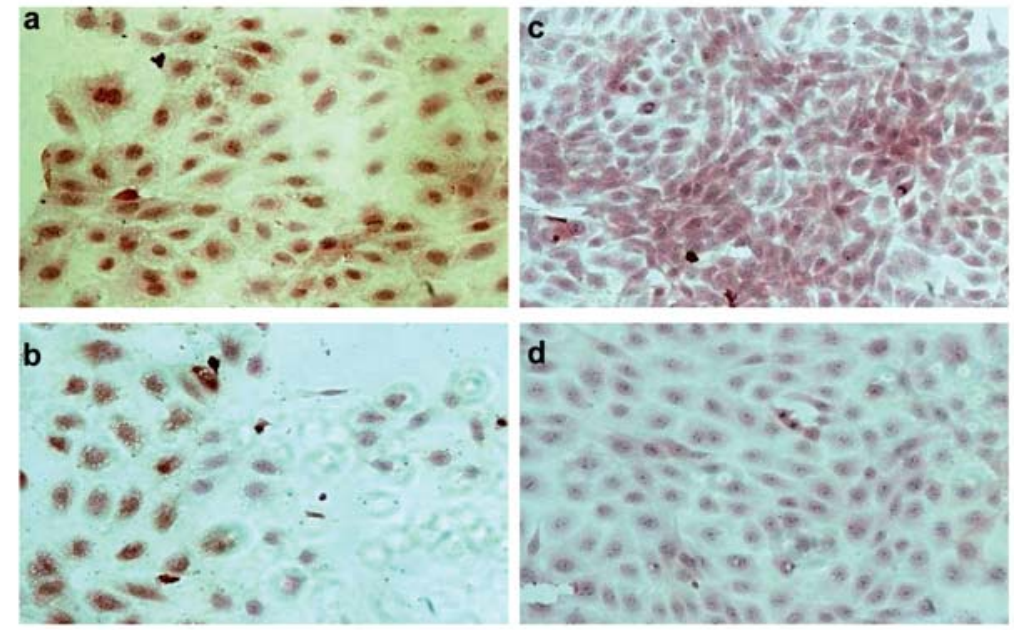

B

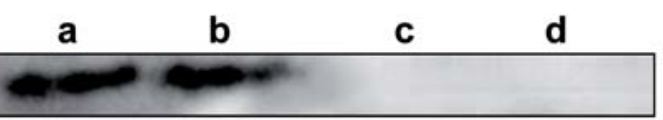

$20 \mathrm{kDa}$

Cleaved Caspase-3

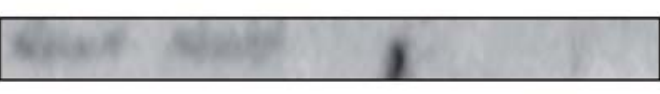

$36 \mathrm{kDa}$

$\beta$-actin

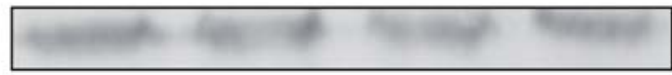

$42 \mathrm{kDa}$

C

a

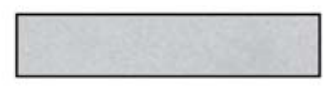

Cytochrome c

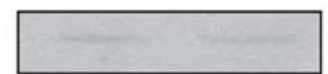

c

d

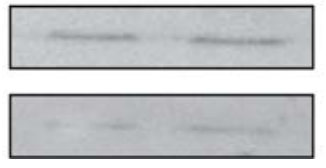

$29 \mathrm{kDa}$

$15 \mathrm{kDa}$

Figure 4. Apoptotic signaling pathway. (A) Immunohistochemical staining of caspase-3, -9 and -8 in A-549 cells (a, b and c, respectively). A-549 parental cells were used as ncontrol (d). (B) Western blotting. Cytoplasmic extracts from A-549/TE* (a), T-84/TE* (b), A-549 (c) and T-84 cells (d) were prepared to determine cleaved caspase proteins. The filter was probed with $B$-actin antibody in order to determine if the amount of proteins in each lane was comparable. (C) Western analysis performed on mitochondrial and cytosol protein fractions. Cytosolic fraction from A-549/TE* (a) and T-84/TE* (b) and mitochondrial fractions from A-549/TE* (c) and T-84/TE* (d) were assayed for cytochrome $\mathrm{c}$ at 3 day. Cytochrome c release to the cytoplasm is shown.

and ' $\mathrm{I}-84 / \mathrm{I}$ 'E cells showed a signiticant decrease in mitochondrial transmembrane potential $(\mathrm{p}<0.05)$, thus indicating an increase in mitochondrial membrane permeability after $E$ gene treatment (Fig. 3A). Moreover, morphological changes of mitochondria were observed by TEM analysis. The most relevant feature found in A-549- and T-84-transfected cells was the presence of dilated mitochondria with clear matrices and disrupted cristae. In contrast, control cells showed unaltered mitochondria (Fig. 3B).

E gene induces caspase protein expression. Inmunohistochemical analysis showed caspase-3- and -9-positive staining of A-549- and T-84-transfected cells. In contrast, caspase-8 study was negative in both transfected cells (Fig. 4A). Western blot analysis showed presence of cleaved caspase- 9 and -3 in $E$ gene-transfected cells (Fig. 4B) and a cytochrome c release to cytoplasm (Fig. 4C). These findings strongly suggest that $E$ gene therapy system may upregulate caspase-3 and -9 expression in the transfected tumour cells and promotes apoptosis by mitochondrial pathway.
Combined E gene-cytotoxic therapy induced growth disturbance on A-549 and T-84 cell. After establishing the effect of $E$ gene on the lung and colorectal cancer cells growth, we investigated its use in a combined therapy with conventional cytotoxic drugs. Non-transfected A-549 cells treated with Pacl, Car or Gem and non-transfected T-84 cells treated with 5FU/FA/Oxa or 5FU/FA/CPT-11 showed a significant reduction in cell viability. A-549/TE* A-549/TE**, T-84/TE* and $\mathrm{T}-84 / \mathrm{TE}^{* *}$ cells showed a greater rate of proliferation inhibition with the combined therapy than was observed with the drugs or $E$ gene alone. Fig. 5 shows that Gem induced a significant growth decrease in A-549 cells. This proliferation inhibition was time- and concentration-dependent, finding the greatest inhibition at day 7 and at the highest concentration $(36.9 \pm 2.6 \%)$. Growth inhibition of A-549/TE** treated with $1 \mu \mathrm{M}$ Gem was $15.5 \pm 1.6 \%$ greater than that of A-549 treated with $100 \mu \mathrm{M}$ Gem. Similar findings were observed with Car, although the proliferation inhibition of A-549/TE* cells at doses of $50 \mu \mathrm{M}$ Car was similar to the sum of effects of the separate drug and $E$ gene treatments (Fig. 5). On the other hand, Pac induced a significant increase in proliferation 

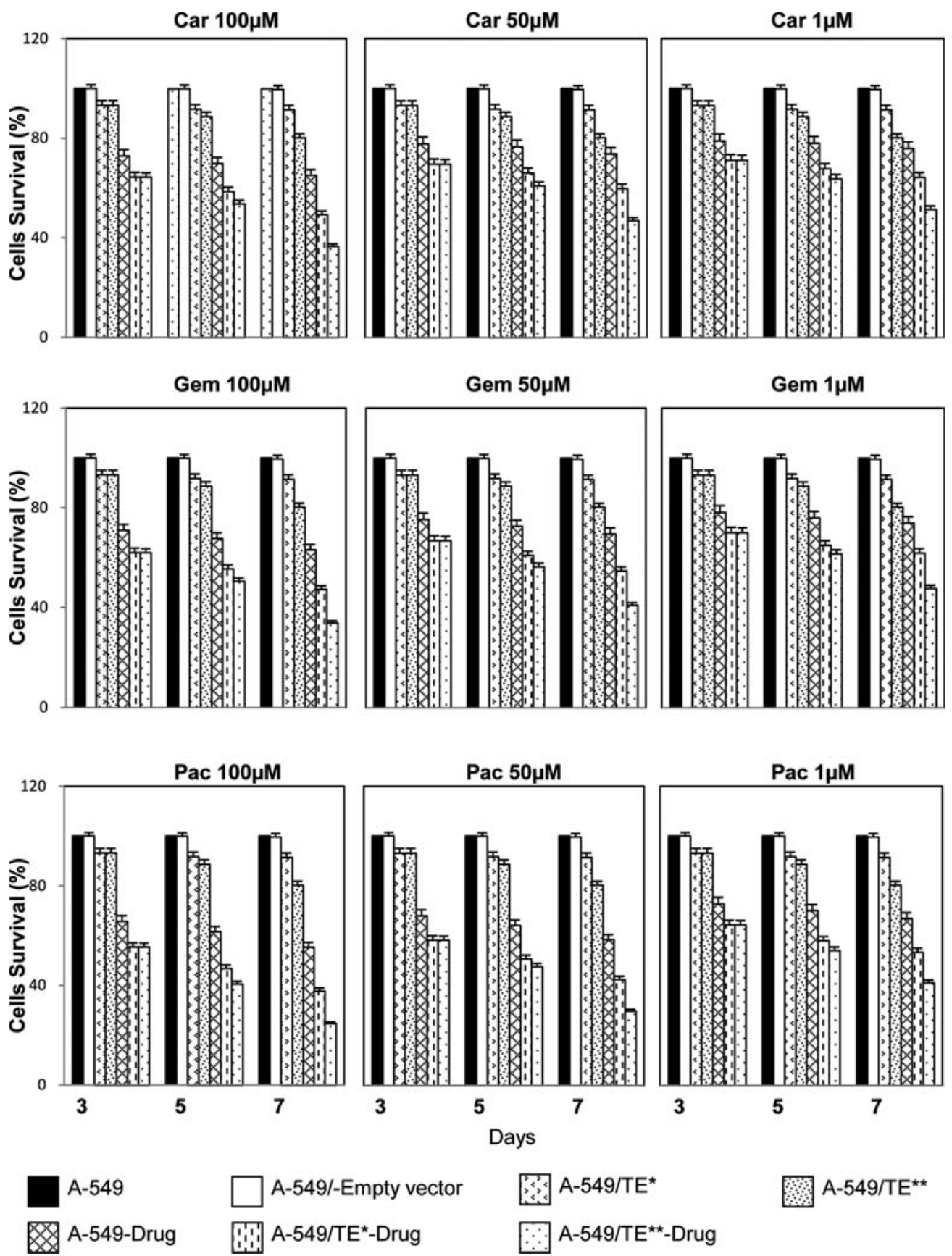

Figure 5. Combined therapy (cytotoxic drugs and $E$ gene transfection) in A-549 cells. Cytotoxic drugs Car, Gem and Pac were used at the indicated concentrations in A-549 parental cells, A-549/TE* and A-549/TE**. Values at 3, 5 and 7 days represent means \pm SD of quadruplicate cultures.

inhibition when combined with the $E$ gene (Fig. 5). The effect of the Pac $100 \mu \mathrm{M}-E$ gene combination A-549/ $\mathrm{TE}^{* *}(75.3 \% \pm 3.3)$ was greater than the sum of the separate effects of $100 \mu \mathrm{M}$ Pac $(44.7 \pm 2.4 \%)$ and continuous $E$ gene transfection $(19.7 \pm 2.0 \%)$ on A-549 cells. This enhancement of effects was also observed with this combined therapy at lower Pac concentrations. Thus, the lowest concentration of Pac1 $(1 \mu \mathrm{M})$ induced $46.6 \pm 2.5 \%$ and $58.8 \pm 3.1 \%$ proliferation inhibition in A-549/TE* and A-549/TE** cells, respectively, i.e., $1.9 \pm 0.4 \%$ and $14.2 \pm 1.4 \%$ greater proliferation inhibition than that obtained with $100 \mu \mathrm{M}$. Because the highest antiproliferative effect was obtained with the combined $E$-genePac therapy, the following experiments were conducted using this combination. To study the possible synergistic/additive effects of $E$ gene and drug combination in colon cancer cells, T-84 cells were exposed to $E$ gene transfection, to different concentrations of 5FU/FA/CPT-11 and 5FU/FA/Oxa alone, and in combination of both. The combined therapy of $E$ gene and different concentrations of 5FU/FA/CPT-11 or 5FU/FA/ Oxa were evaluated at different time-points. Results showed significant synergistic toxicity at 7 day, as compared to any agent alone (Figs. 6 and 7). Growth inhibition of T-84/TE** treated with 500:5:10 $\mu \mathrm{M}$ 5FU/FA/CPT-11 and 5:5:10 $\mu \mathrm{M}$ $5 \mathrm{FU} / \mathrm{FA} / \mathrm{CPT}-11$ was $15 \pm 1.7 \%$ and $5.6 \pm 0.6 \%$, respectively, greater than that of T-84 treated with 5000:5:200 $\mu \mathrm{M} 5 \mathrm{FU} /$ FA/CPT-11 (Fig. 6). The results revealed that the proliferation inhibition when using alone 5FU/FA/Oxa to the dose 5000:5:1000 $\mu \mathrm{M}(48.6 \pm 3.2 \%)$ was similar to the results 

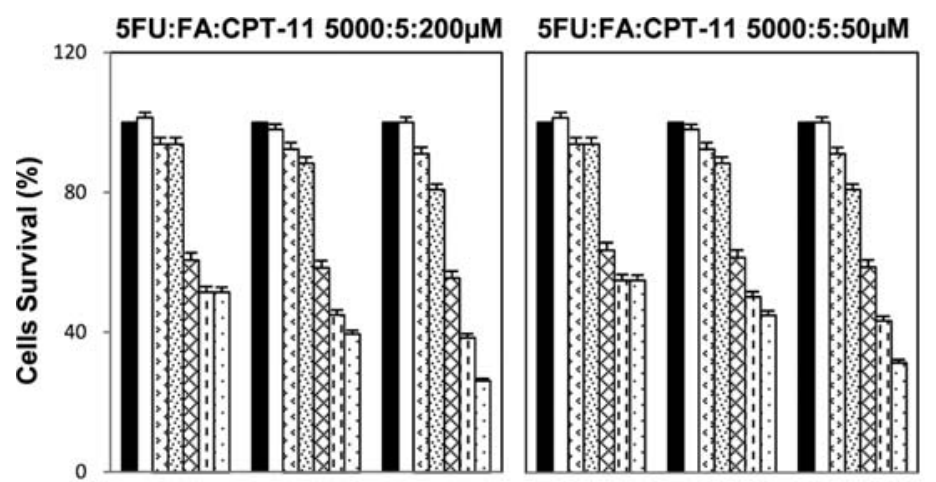

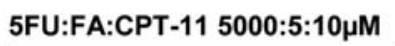
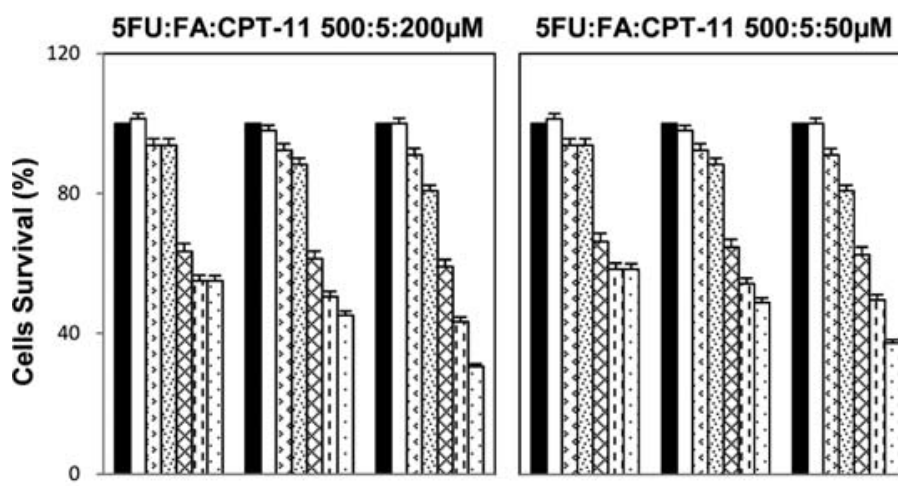

5FU:FA:CPT-11 500:5:10 $\mu \mathrm{M}$
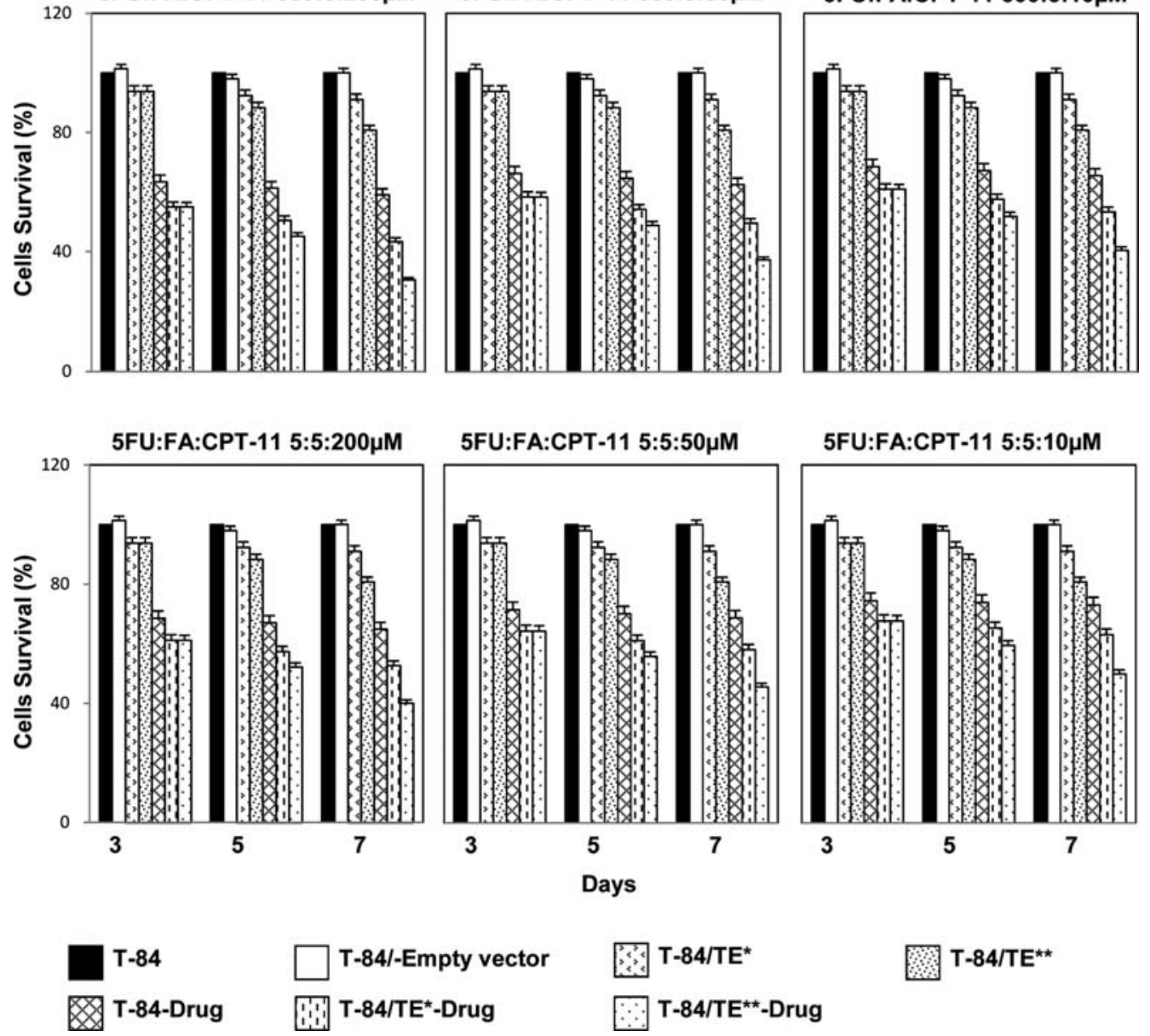

5FU:FA:CPT-11 5:5:10 $\mu \mathrm{M}$
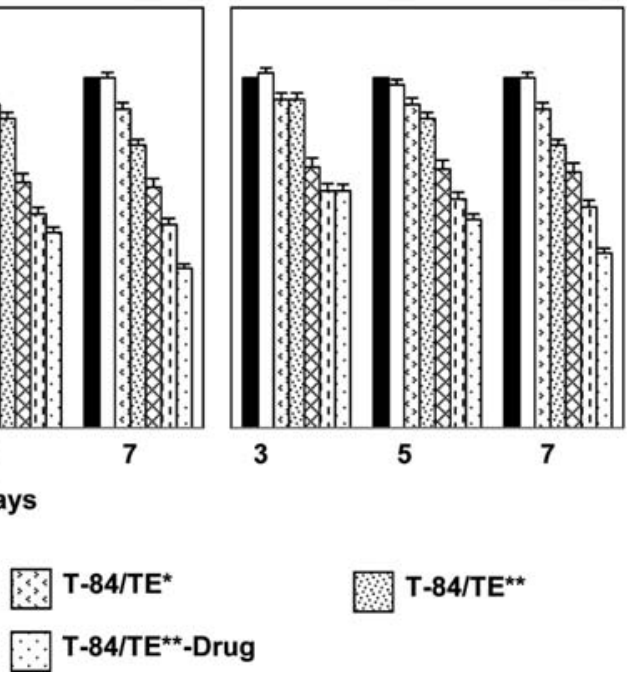

T-84/TE**

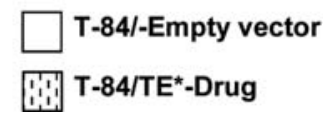

Figure 6. Combined therapy (cytotoxic drugs and $E$ gene transfection) in T-84 cells. Cytotoxic drugs 5FU:FA:CPT-11 were used at the indicated concentrations in T-84 parental cells, T-84/TE ${ }^{*}$ and T-84/TE ${ }^{* *}$. Values at 3, 5 and 7 days represent means \pm SD of quadruplicate cultures.

obtained to dose 500:5:0.5 $\mu \mathrm{M}(58.3 \pm 3.2 \%)$ and 5:5:10 $\mu \mathrm{M}$ $(55.7 \pm 3.6 \%)$ in $\mathrm{T}-84 / \mathrm{TE}^{* *}(\mathrm{p}<0.05)$ (Fig. 7). Because the highest anti-proliferative effect was obtained with the combined $E$ gene-Pac (A-549) and $E$ gene-5Fu/FA/Oxa (T-84) therapy, the following combined therapy experiments were conducted using this drug.

Apoptosis analysis. Significant differences in \% apoptosis were found among control A-549 cells $(0.7 \pm 0.1 \%)$, A-549/ TE* cells $(8.9 \pm 0.6 \%)$, cytotoxic drug-treated A-549 cells $(100 \mu \mathrm{M})(73.4 \pm 4.2 \%)$ and cells receiving the $E$ gene $1-\mu \mathrm{M}$ Pac combined therapy $(67 \pm 3.4 \%)$ (Fig. 8A). Similar results are shown in T-84 cells $(0.1 \%), \mathrm{T}-84 / \mathrm{TE}^{*}$ cells $(18 \pm 0.9 \%)$, cytotoxic drug-treated T-84 cells (5000:5:1000 $\mu \mathrm{M})(38 \pm 2.7 \%)$ and cells receiving the $E$ gene 500:5:0.5- and 5:5:10- $\mu \mathrm{M}$ 5FU/FA/Oxa combined therapy $(75.5 \pm 3.3$ and $3 \pm 0.5 \%$, respectively) (Fig. 8B). Treatment with empty vector had no significant apoptotic effect on these cells.

\section{Discussion}

Although in recent years there has been a progress in the development of new therapies and an improvement in the traditional treatments, the prognosis for patients with advanced colon or lung cancer remains poor. Unfortunately, the habitually late diagnosis of these tumours alongside the 

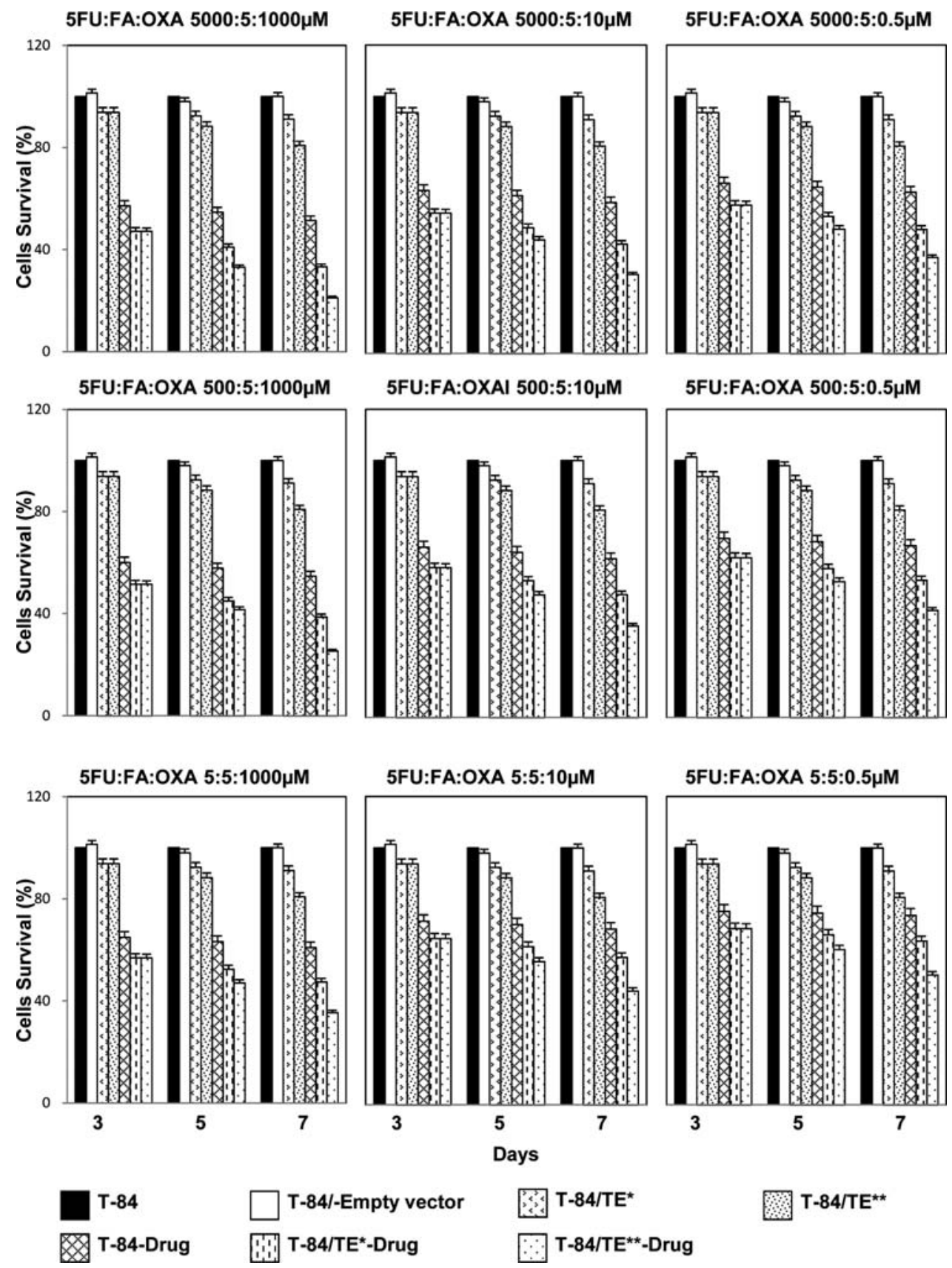

Figure 7. Combined therapy (cytotoxic drugs and $E$ gene transfection) in T-84 cells. Cytotoxic drugs 5FU:FA:Oxa were used at the indicated concentrations in T-84 parental cells, T-84/TE* and T-84/TE**. Values at 3,5 and 7 days represent means \pm SD of quadruplicate cultures.

ineffective and harmful effects of the conventional adjuvant treatments are responsible for the failure in the long-term survival increase after surgical resection. Thus, research related to the association of some anticancer strategies, including gene therapy and antitumour drugs, is necessary (22).

There is strong evidence that gene therapy can increase the efficiency of cytotoxic drugs in cancer treatment. In colon cancer, as shown recently by Yuan et al (23), the use of a combined therapy with mPNAS-4, a novel pro-apoptotic gene, associated to cisplatin led to an increase in tumour cell apoptosis in vitro and in vivo. The ability to target specific genes to cancer cells by promoters makes gene therapy a powerful tool to improve the response of the patient. The use of the urokinase plasminogen activator receptor (UPAR) promoter has been successfully used in colon cancer by the implication of the RAS signaling pathway in their carcinogenesis processes (24). Other authors (25) have successfully tested the carcinoembryonic antigen promoter (CEA)-cytosine deaminase gene expression for colon cancer treatment. Recently, He et al (26) demonstrated that the use of an AAV-mediated human interferon $\beta$ (IFN-B) gene driven by hTERT promoter decreased colorectal and lung cancer cell viability, but not normal cells. In addition, this strategy induced tumor cell apoptosis mediated by the activation of caspase and by the release of cytochrome $\mathrm{c}$ in colorectal and lung cancer in mice resulting in tumor cells death in vivo. Research in lung cancer aims to improve the 

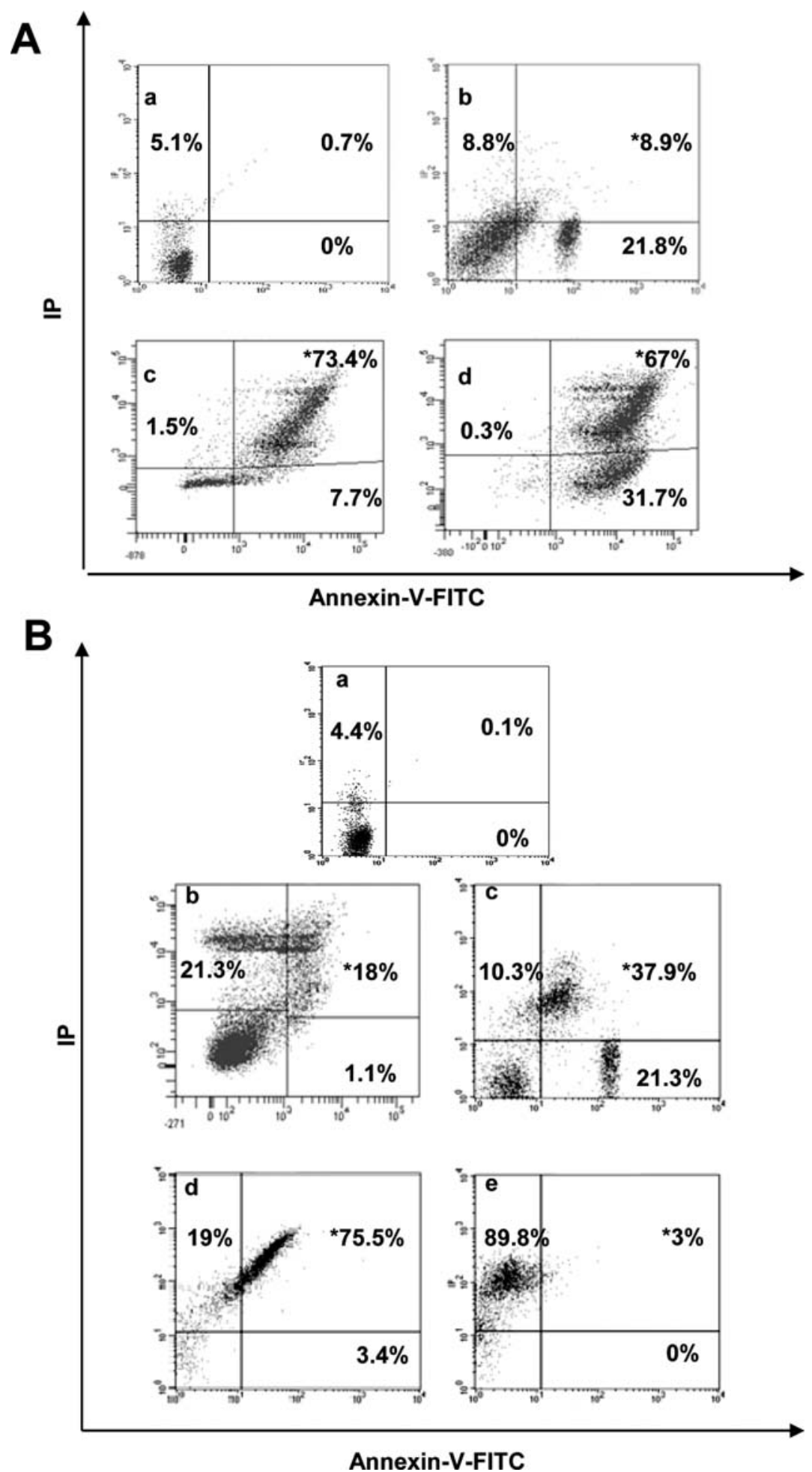

Figure 8. Apoptosis induced by combined therapy with $E$ gene and cytotoxics in A-549 and T-84 cells. (A) Representative FACScan showing apoptosis in A-549 cells after combined therapy at 3 day. (a) Parental A-549 cells; (b) A-549/TE*; (c) A-549-Pac 100 $\mu$ M; (d) A-549/TE*-Pac $1 \mu$ M. (B) Representative FACScan showing apoptosis in T-84 cells after combined therapy at 3 day. (a) Parental T-84 cells; (b) T-84/TE*; (c) T-84-5FU/FA/Oxa 5000:5:1000 $\mu$ M; (d) T-84/TE*-5FU/FA/Oxa 500:5:0.5 $\mu \mathrm{M}$; (e) T-84/TE*-5FU/FA/Oxa 5:5:10 $\mu \mathrm{M}$. These data are mean results of four separate experiments. Values represent means \pm SD of quadruplicate cultures. Level of significance compared to control cells; ${ }^{*} \mathrm{p}<0.05$.

outcome of the gene therapy strategies. Recent studies showed that $\mathrm{NF}-\mathrm{\kappa B}$ inducing kinase (NIK) is aberrantly expressed at the pre-translational level in NSCLC cell lines. Depletion of NIK by RNA interference remarkably diminished nuclear NF-KB DNA binding activity and reporter gene expression. These results indicate that NIK plays a key role in constitutive NF- $\mathrm{B}$ acti-vation in NSCLC cells and implicate NIK as a molecular target for lung cancer therapy (27). On the other hand, Sher et al (28) have developed a specific promoter amplification system, called VISA (VP16GAL4-WPRE integrated systemic amplifier) to enhance the surviving promoter activity (highly expressed in many 
cancers but not in normal adult tissues) in lung cell lines in vitro and in lung tumor tissue in vivo. Since survivin is a cancer specific promoter, the amplification from VISA made the activity level of survivin-VISA vector compa-rable to CMV promoter in lung cancer cells, but in normal cells, survivin-VISA was still much weaker than that of the CMV promoter. Combining the cancer-specific promoter with the VISA system might enable novel strategies to treat different cancers without toxicity to normal human tissues.

In this context, we have previously demonstrated that gef gene, a gene which does not need a prodrug, showed antitumour activity in breast cancer cells by inducing apoptosis (29), and that this gene is able to enhance the effect of drugs in lung cancer cells (11). Recently, we have demonstrated that a bacteriophage gene ( $E$ gene) has also antitumour activity (17). Interestingly, we have demonstrated this gene is able to reduce the chemotherapy dose classically used in the treatment of colon and lung cancer. Now, we are investigating the regulation of its expression through promoters in order to achieve a specific activity in different types of tumors. Using a eukaryotic expression vector (pcDNA3.1) $(30,31), E$ gene was expressed in A-549 and T-84 cells which showed a clear decrease in cell growth rate. The largest reduction in proliferation was obtained with continual transfection of the $E$ gene and after the longest period (7 days). The in vitro experiments designed to investigate whether $E$ gene could induce apoptosis of A-549 and T-84 cells were positive. Because apoptosis may occur via either death-receptordependent (extrinsic) or mitochondrial (intrinsic) pathways we carried out experiments to determine the specific activate apoptosis pathway in colon and lung cancer cells. The apoptotic mitochondrial pathway is mediated by Bcl-2 family proteins which disrupt the mitochondria membrane potential and result in the release of apoptogenic factors (32). Transfection of A-549 and T-84 cells with $E$ gene induced modulation of mitochondrial membrane potential, activation of caspases- 9 and -3 and cytochrome $\mathrm{c}$ release to cytoplasm suggesting that $E$ gene induced mitochondria-mediated apoptosis. The experiments of Hengartner et al (33) confirm that the apoptosis by activation of mitochondrial pathway induces morphologic alterations. Our morphologic analysis in transfected cells supports the hypothesis of the mitochondrial pathway induced by $E$ gene because multiple dilated mitochondria with clear matrices and disrupted cristae were observed. The association of gene therapy and antitumour drugs has been proposed as a strategy to enhance the antitumour effect of drugs in the treatment of refractory or advance cancers (11). Combined therapy with drugs (cisplatin, gemcitabine, paclitaxel or vinblastine) and Reovirus type 3 dearing strain (ReoT3D) has been assayed in lung cancer and Pac has showed higher efficacy when combined with ReoT3D in this tumour (34). On the other hand, CPT-11 needs to be converted into SN-38 (7-ethyl-10hydroxycamptothecin) by the enzyme carboxylesterase (CE) to be fully active. To increase the anti-tumour effect of CPT-11 Oosterhoff et al (35) constructed a replicationdeficient adenoviral vector Ad.C28-sCE2 containing a fusion gene encoding a secreted form of human liver the enzyme carboxylesterase targeted to the surface antigen epithelial cell adhesion molecule (EpCAM) that is highly expressed on most colon carcinoma cells. Treatment with non-toxic concentrations of CPT-11 resulted in growth inhibition comparable to treatment with $\mathrm{SN}-38$. Our results show that $E$ gene enhances the apoptosis-inducing potential of chemotherapeutic drugs (Pac, Gem and Car) in lung cancer cells (A-549 cells) suggesting that relatively low levels of a chemotherapeutic agent might be combined with the $E$ gene to offer an effective and antitumour treatment. The greatest effect was obtained to the association $E$ gene and Pac. Moreover, we tested the combination of $5 \mathrm{FU} / \mathrm{FA} / \mathrm{CPT}-11$ or $5 \mathrm{FU} / \mathrm{FA} / \mathrm{Oxa}$ and $E$ gene in colon cancer cells. Growth analyses of the T-84 showed that the combined therapy induced significant growth inhibition. The largest reduction was obtained with the use of $E$ gene and 5FU/FA/Oxa. This inhibition was greater than that obtained using the gene therapy or chemotherapy alone. These results showed that the combination of $E$ gene and 5FU/FA/Oxa enhanced cell growth inhibition in $\mathrm{T}-84$ cells, suggesting its therapeutic potential in colon cancer. These data support the hypothesis that growth inhibition of drug-induced A-549 and T-84 cells may be enhanced by simultaneous $E$ gene therapy, allowing a reduction in the dose of cytotoxic agent applied to the tumours.

In conclusion, we have developed a novel experimental therapeutic strategy using gene therapy with $E$ and chemotherapeutic drugs for the treatment of human lung and colon cancer. $E$ gene was able to induce the apoptotic mitochondrial pathway in A-549 and T-84 cells. In addition, combined $E$ gene/drug therapy enhanced cell growth inhibition of these cancer cells. Furthermore, the utility of this combined therapy suggests that $E$ gene may be a new candidate for an effective strategy for lung and colon cancer treatment, specially for patients with a poor prognosis.

\section{Acknowledgments}

The authors are grateful to Dr R. Luque of the Oncology Department, Virgen de las Nieves Hospital, Granada, for performing the chemotherapy treatments. The study was supported by the Consejería de Salud, Junta de Andalucía, Project no. PI-0338).

\section{References}

1. Kosmidis P, Fountzilas G, Baka S, Samantas E, Dimopoulos AM, Gogas H, Skarlos D, Papacostas P, Boukovinas J, Bakogiannis Ch, Pantelakos P, Athanasiou H, Misailidou D, Tsekeris $\mathrm{P}$ and Pavlidis N: Combination chemotherapy with paclitaxel and gemcitabine followed by concurrent chemoradiotherapy in nonoperable localized non-small cell lung cancer. A Hellenic cooperative oncology group (HeCOG) phase II study. Anticancer Res 27: 4391-4395, 2007.

2. Felip E and Rosell R: Pemetrexed as second-line therapy for advanced non-small-cell lung cancer (NSCLC). Ther Clin Risk Manag 4: 579-585, 2008.

3. Cohen DJ and Hochster HS: Rationale for combining biotherapy in the treatment of advanced colon cancer. Gastrointest Cancer Res 2: 145-151, 2008.

4. Díez-Fernández R, Salinas Hernández P and Girón-Duch C: A review of chemotherapy for metastatic colon cancer. Farm Hosp 30: 359-369, 2006

5. Carrato A, Gallego-Plazas J and Guillén-Ponce C: Capecitabine plus oxaliplatin for the treatment of colorectal cancer. Expert Rev Anticancer Ther 8: 161-174, 2008. 
6. Shieh GS, Shiau AL, Yo YT, Lin PR, Chang CC, Tzai TS and Wu CL: Low-dose etoposide enhances telomerase-dependent adenovirus-mediated cytosine deaminase gene therapy through augmentation of adenoviral infection and transgene expression in a syngeneic bladder tumor model. Cancer Res 66: 9957-9966, 2006.

7. Deharvengt S, Rejiba S, Wack S, Aprahamian M and Hajri A: Efficient electrogene therapy for pancreatic adenocarcinoma treatment using the bacterial purine nucleoside phosphorylase suicide gene with fludarabine. Int J Oncol 30: 1397-1406, 2007.

8. Prados J, Melguizo C, Rama AR, Ortiz R, Segura A, Boulaiz H, Vélez C, Caba O, Ramos JL and Aránega A: Gef gene therapy enhances the therapeutic efficacy of Doxorubicin to combat growth of MCF-7 breast cancer cells. Cancer Chemother Pharmacol 66: 69-78, 2010.

9. Liu D, Kojima T, Ouchi M, Kuroda S, Watanabe Y, Hashimoto Y, Onimatsu H, Urata Y and Fujiwara T: Preclinical evaluation of synergistic effect of telomerase-specific oncolytic virotherapy and gemcitabine for human lung cancer. Mol Cancer Ther 8: 980-987, 2009

10. Wu JQ, Zhao WH, Li Y, Zhu B and Yin KS: Adeno-associated virus mediated gene transfer into lung cancer cells promoting CD40 ligand-based immunotherapy. Virology 368: 309-316, 2007.

11. Prados J, Melguizo C, Rama A, Ortiz R, Boulaiz H, RodriguezSerrano F, Caba O, Rodriguez-Herva JJ, Ramos JL and Aránega A: Combined therapy using suicide gef gene and paclitaxel enhances growth inhibition of multicellular tumour spheroids of A-549 human lung cancer cells. Int J Oncol 33: 121-127, 2008 .

12. Gutermann A, Mayer E, von Dehn-Rothfelser K, Breidenstein C, Weber M, Muench M, Gungor D, Suehnel J, Moebius U and Lechmann M: Efficacy of oncolytic herpesvirus NV1020 can be enhanced by combination with chemotherapeutics in colon carcinoma cells. Hum Gene Ther 17: 1241-1253, 2006.

13. Guo J, Verma UN, Gaynor RB, Frenkel EP and Becerra CR: Enhanced chemosensitivity to irinotecan by RNA interferencemediated down-regulation of the nuclear factor-kappaB p65 subunit. Clin Cancer Res 10: 3333-3341, 2004.

14. Buckley K J and Hayashi M: Role of premature translational termination in the regulation of expression of the phi X174 lysis gene. J Mol Biol 198: 599-607, 1987.

15. Maratea D, Young K and Young R: Deletion and fusion analysis of the phage phi X174 lysis gene $E$. Gene 40: 39-46, 1985

16. Witte A, Wanner G, Bläsi U, Halfmann G, Szostak M and Lubitz W: Endogenous transmembrane tunnel formation mediated by phi X174 lysis protein E. J Bacteriol 172: 41094114, 1990.

17. Ortiz R, Prados J, Melguizo C, Rama AR, Segura A, RodríguezSerrano F, Boulaiz H, Hita F, Martinez-Amat A, Madeddu R, Ramos JL and Aranega A: The cytotoxic activity of the phage $\mathrm{E}$ protein suppress the growth of murine B16 melanomas in vitro and in vivo. J Mol Med 87: 899-911, 2008.

18. Dasgupta P, Kinkade R, Joshi B, Decook C, Haura E and Chellappan S: Nicotine inhibits apoptosis induced by chemotherapeutic drugs by up-regulating XIAP and survivin. Proc Natl Acad Sci USA 103: 6332-6337, 2006.

19. Ulukaya E, Ozdikicioglu F, Oral AY and Demirci M: The MTT assay yields a relatively lower result of growth inhibition than the ATP assay depending on the chemotherapeutic drugs tested. Toxicol In Vitro 22: 232-239, 2008.

20. Ganten TM, Koschny R, Sykora J, Schulze-Bergkamen H, Büchler P, Haas TL, Schader MB, Untergasser A, Stremmel W and Walczak H: Preclinical differentiation between apparently safe and potentially hepatotoxic applications of TRAIL either alone or in combination with chemotherapeutic drugs. Clin Cancer Res 12: 2640-2646, 2006.
21. Fischel JL, Etienne MC, Formento P and Milano G: Search for the optimal schedule for the oxaliplatin/5-fluorouracil association modulated or not by folinic acid: preclinical data. Clin Cancer Res 4: 2529-2535, 1998.

22. Fang B and Roth JA: The role of gene therapy in combined modality treatment strategies for cancer. Curr Opin Mol Ther 5: 475-482, 2003.

23. Yuan Z, Yan F, Wang YS, Liu HY, Gou LT, Zhao XY, Lai ST, Deng HX, Li J, Ding ZY, Xiong SQ, Kan B, Mao YQ, Chen LJ, Wei YQ and Zhao X: PNAS-4, a novel pro-apoptotic gene, can potentiate antineoplastic effects of cisplatin. Cancer Chemother Pharmacol 65: 13-25, 2009.

24. Teimoori-Toolabi L, Azadmanesh K, Amanzadeh A and Zeinali S: Selective suicide gene therapy of colon cancer exploiting the urokinase plasminogen activator receptor promoter. BioDrugs 24: 131-146, 2010

25. Zhang G, Liu T, Chen YH, Chen Y, Xu M, Peng J, Yuan J and Zhang X: Tissue specific cytotoxicity of colon cancer cells mediated by nanoparticle-delivered suicide gene in vitro and in vivo. Clin Cancer Res 15: 201-207, 2009.

26. He LF, Wang YG, Xiao T, Zhang KJ, Li GC, Gu JF, Chu L, Tang WH, Tan WS and Liu XY: Suppression of cancer growth in mice by adeno-associated virus vector-mediated IFN-beta expression driven by hTERT promoter. Cancer Lett 286: 196-205, 2009.

27. Saitoh Y, Martínez Bruyn VJ, Uota S, Hasegawa A, Yamamoto N, Imoto I, Imoto I, Inazawa J and Yamaoka S: Overexpression of NF-kappaB inducing kinase underlies constitutive NF-kappaB activation in lung cancer cells. Lung Cancer (In press).

28. Sher YP, Tzeng TF, Kan SF, Hsu J, Xie X, Han Z, Lin WC, Li LY and Hung MC: Cancer targeted gene therapy of BikDD inhibits orthotopic lung cancer growth and improves long-term survival. Oncogene 28: 3286-3295, 2009.

29. Boulaiz H, Prados J, Melguizo C, García AM, Marchal JA, Ramos JL, Carrillo E, Vélez C and Aranega A: Inhibition of growth and induction of apoptosis in human breast cancer by transfection of gef gene. Br J Cancer 89: 192-198, 2003.

30. Han TK and Dao ML: Enhancement of salivary IgA response to a DNA vaccine against Streptococcus mutans wall-associated protein A in mice by plasmid-based adjuvants. J Med Microbiol 56: 675-680, 2007

31. Gao X, Wu L and O'Neil RG: Temperature-modulated diversity of TRPV4 channel gating: activation by physical stresses and phorbol ester derivatives through protein kinase C-dependent and -independent pathways. J Biol Chem 278: 27129-27137, 2003.

32. Kim R: Recent advances in understanding the cell death pathways activated by anticancer therapy. Cancer 103: 1551-1560, 2005.

33. Hengartner MO: The biochemistry of apoptosis. Nature 407: 770-776, 2000.

34. Sei S, Mussio JK, Yang QE, Nagashima K, Parchment RE, Coffey MC, Shoemaker RH and Tomaszewski JE: Synergistic antitumor activity of oncolytic reovirus and chemotherapeutic agents in non-small cell lung cancer cells. Mol Cancer 8: 47, 2009.

35. Oosterhoff D, Overmeer RM, de Graaf M, van der Meulen IH, Giaccone G, van Beusechem VW, Haisma HJ, Pinedo HM and Gerritsen WR: Adenoviral vector-mediated expression of a gene encoding secreted, EpCAM-targeted carboxylesterase-2 sensitises colon cancer spheroids to CPT-11. Br J Cancer 92: 882-887, 2005. 